\title{
GAMBARAN SUPERVISI, IKLIM KERJA SERTA KEPUASAN KERJA KARYAWAN PT. TRIBUANA REKAYASA BANDUNG
}

\author{
Devi Robissalami \\ Universitas Pendidikan Indonesia \\ devirobissalami@student.co.upi.edu \\ Hj. Sumiyati, SE.,M.Si \\ Universitas Pendidikan Indonesia \\ sumiyati@upi.edu \\ Drs. H. Eded Tarmedi, MA \\ Universitas Pendidikan Indonesia \\ tarmedi@upi.edu
}

\begin{abstract}
ABSTRAK
Tujuan - Tujuan dari penelitian ini adalah untuk mengetahui pengaruh supervisi dan iklim kerja terhadap kepuasan kerja karyawan

Desain / metodologi / pendekatan - Penelitian ini dilakukan pada jangka waktu kurang dari 1 tahun, maka desain penelitian adalah desain cross-sectional. Dan metode yang digunakan adalah survei exolanatory, dan populasi 67 karyawan.Teknik analisis yang digunakan adalah deskriptif, kuesioner digunakan sebagai instrumen penelitian untuk mengumpulkan data dari responden.

Temuan - berdasarkan hasil penelitian menggunakan analisis regresi linear ganda, didapatkan hasil bahwa terdapat pengaruh positif antara supervisi dan iklim kerja berpengaruh terhadap kepuasan kerja karyawan.

Orisinilitas/nilai - penelitian ini memberikan dasar untuk memahami dampak dari supervisi dan iklim kerja terhadap kepuasan kerja karyawan. Perbedaan penelitian ini dengan penelitian sebelumnya adalah pada objek, variabel, teori serta referensi yang digunakan oleh peneliti dengan peneliti sebelumnya.
\end{abstract}

Kata kunci: Supervisi, Iklim Kerja, Kepuasan Kerja Karyawan

Jenis Artikel: Penelitian

\section{ABSTRACT}

Purpose - The purpose of this study is to determine the effect of supervision and working climate on employee job satisfaction

Design / methodology / approach - This research was conducted in less than 1 year period, the research design is cross-sectional design. The method used is exolanatory survey, and population 67 employees. The analysis technique used is descriptive, the questionnaire is used as a research instrument to collect data from respondents.

Findings - based on the results of the study using multiple linear regression analysis, the result that there is a positive influence of supervision and work climate on employee job satisfaction.

Originality / value - this study provides a basis for find out the impact of supervision and working climate on employee job satisfaction. The difference of this study with previous research is on the objects, variables, theories and the references.

Keywords: Supervision, Working Climate, Employee Job Satisfaction

Article Type: Research Paper 


\section{Pendahuluan}

Kepuasan kerja karyawan sangat penting dalam mencapai tujuan sebuah perusahaan, untuk keberlangsungan hidup perusahaannya. dengan memiliki karyawan yang puas terhadap pekerjaanmaka akan dapat meningkatkan kinerja dan prestasinya. Kepuasan dalam bidang sumber daya manusia di suatu organisasi, kurangnya kepuasan kerja merupakan prediktor utama karyawan untuk berhenti dari pekerjaan (Tella; 2017). Rendahnya perhatian perusahaan terhadap kepuasan kerja karyawannya akan menimbulkan efek negatif bagi karyawan itu sendiri yang menyebabkan kerugian bagi perusahaan, hal itu dikarenakan kinerja yang menurun yang berdampak langsung pada output dan perusahaan baik dari segi kualitas maupun kuantitas.

Kepuasan kerja yang buruk dapat menjadi masalah yang harus diperhatikan dan diselesaikan oleh pihak perusahaan karena kepuasan kerja karyawan dapat mempengaruhi kualitas dan kuantitas perusahaan dalam menghadapi persaingan dan menjadi faktor penting dalam mencapai tujuan perusahaan. Permasalahan tersebut sering terjadi dan tidak boleh terus dibiarkan apabila perusahaan ingin terus berkembang. Permasalahan kepuasan kerja dialami juga di PT. Tribuana Rekayasa yang mana mengalami permasalahan internal yang menyangkut masalah kepuasan kerja karyawannya yang rendah hal ini juga buruk pada produktivitas perusahaan tersebut karena perusahan dapat terganggu dalam kinerja dan produktivitasnya. Kepuasan kerja dalam sebuah organisasi dibeberapa negara pada umumnya mengalami penurunan kepuasan kerja karyawannya, yang disebabkan oleh faktor ekstrinsik yaitu keadaan emosi yang dikendalikan oleh organisasi dan ketidakhadiran karyawan sehingga dapat menyebabkan ketidakpuasan danfaktor Intrinsik faktor kepuasan kerja yang bisa menjadi kekuatan motivasi, meskipun ketidakhadiran mereka tidak selalu memuaskan (Jovicic: 2013).

Di era global ini, persaingan bisnis antar perusahaan sangat ketat, termasuk di bidang jasa. Pelayanan di bidang ini perlu mendapat perhatian khusus, karena ini soal kepuasan jadi pekerja moral yang baik, profesional, disiplin dan bertanggung jawab dalam melakukan tugasnya sangat dibutuhkna (Sumiyati, 2016). Karyawan dalam perusahaan perlu diperhatikan karena sumber daya manusia dalam perusahaan merupakan faktor utama untuk tercapainya target perusahaan yang telah direncanakan. Perhatian dibidang sumber daya manusia tidak boleh diabaikan hal itu merupakan aspek penting untuk merencanakan karyawan agar bekerja lebih efektif dan terus ditingkatkan dalam rangka mencapai tujuan perusahaan (Syamsul Hadi Senen, Sumiyati, Masharyono; 2016). Kepuasan kerja merupakan salah satu bidang yang paling kompleks yang dihadapi perusahaan saat ini ketika dihadapkan untuk mengelola karyawan mereka(Eded, 2016).

Menurut (Veitzal Rivai; 2011:860) faktorfaktor yang digunakan untuk mengukur kepuasan kerja seorang karyawan adalah: (a) isi pekerjaan, penampilan tugas pekerjaan yang aktual dan sebagai kontrol terhadap pekerjaan; (b) supervisi; (c) iklim kerja dan manajemen; (d) kesempatan untuk maju; (e) gaji dan keuntungan dalam bidang finansial lainnya seperti adanya insentif; (f) rekan kerja; dan (g) kondisi pekerjaan.

Faktor supervisi dapat mempengaruhi kepuasan kerja sesuai dengan penelitian yang dilakukan oleh (Sri; 2012) penelitian bertujuan untuk mengetahuipengaruh supervisi pada kepuasan kerja karyawan, hasil penelitian ini menyatakan bahwa supervisi ada pengaruhnya terhadap kepuasan kerja.Semakin baik supervisi diharapkan semakin tinggi pula tingkat kepuasan kerja karyawan.

Selain faktor supervisi, faktor yang juga dapat mempengaruhi kepuasan kerja adalah iklim kerja, seperti yang terjadi di PT. Tribuana Rekayasa Bandung yang merupakan salah satu perusahaan yang bergerak dalam bidang jasa konsultan teknik dan memiliki beberapa bagian divisi.Tidak dipungkiri bahwa PT. Tribuana Rekayasa sendiri banyak mengalami permasalahan.Banyaknya tantangan yang mucul mengakibatkan perusahaan mengalami kemunduran terutama bidang Sumber Daya Manusia itu sendiri. Menurut (Chintala; 2014) bahwa kepuasan kerja berhubungan dengan variabel-variabel akademisi, seperti hubungan interpersonal dengan rekan kerja, kondisi kerja, beban kerja, pengawasan (supervisi), manajemen, membayar, promosi, keamanan kerja, status sosial.

\section{Kajian Pustaka}

\section{Supervisi}

Setiap organisasi tentunya memiliki sebuah tujuan. Supervisi merupakan faktor yang sangat penting dalam perusahaan, supervisi yang baik akan mendukung adanya peningkatan kinerja yang dapat meningkatkan hasil dari perusahaan yang bersangkutan.Pengertian supervisi menurut (Lynne Mc Pherson; 2017).

Supervisi merupakan beban kerja dan kinerja yang bertanggung jawab untuk penciptaan dan pemeliharaan pembelajaran dan pertumbuhan 
supervisi yang dilakukan oleh supervisor. (Akhter; 2016) mendefinisikan supervisi sebagai jumlah dukungan dan bimbingan yang diterima dari manajer. Pendapat lain dikemukakan oleh Agus Dharma; 2014:8) supervisi merupakan kegiatan yang mengkoordinasi pelaksanaan tugas melalui pengarahan dan umpan balik (feed back) yang efektif dan efisien.

Menurut (Salvador; 2016) supervisi didefinisikan sebagai bimbingan dan pengawasan dari seorang ahli atau orang yang lebih berpengalaman. Supervisi juga di definisikan sebagai bimbingan dan pengawasan dari seorang ahli atau orang yang lebih berpengalaman (Deff dan Shahin; 2016).

Fungsi dalam kegiatan supervisi yaitu pekerjaan sosial, supervisi melayani berbagai tujuan. Sebagaimana supervisi merupakan salah satu arena profesional di mana pekerja sosial merefleksikan penggunaan kebijaksanaan dan penilaian (Hughes; 2010). Sedangkan tujuan supervisi sebagaipencegahan stres dan keluar dari pekerjaan, tetapi juga memungkinkan supervisi untuk terus belajar dan berkembang, sehingga mereka menghabiskan lebih banyak waktu bekerja dan tidak merasa bosan (Wosket; 2010).

Model supervisi menurut (Danim Sudaman Khaira; 2011 : 172-173) yaitu terisi dari: 1) Model supervisi konvensional (tradisonal), 2) Model supervisi ilmiah, 3) Mmodel supervisi klinis, dan 4) Model supervisi artistic. Sedangkan menurut (Agus Dharma; 2014) supervisi memiliki beberapa dimensi yaitu: a) Koordinasi; b) Pengarahan; c) Pemeriksaan; d) Mentoring; e) Umpan balik (feed back).

\section{Iklim Kerja}

Iklim kerja merupakan persepsi karyawan tentang bagaimana mereka diperlakukan dan dikelola dalam organisasi, penting ketika organisasi mencoba untuk memotivasi karyawan untuk mengalokasikan dan meningkatkan upaya mereka di tempat kerja (Boudrias et al; 2016). Sedangkan menurut (Handoko; 2013) iklim kerja yaitu lingkungan manusia di mana para karyawan organisasi melaksanakan pekerjaan mereka. Iklim tidak dapat dilihat dan disentuh tetapi iklim tersebut ada dan akan mempengaruhi segala sesuatu yang terjadi dalam organisasi.

Menurut (Frans Mardi; 2009:320) peningkatan kualitas iklim kerja perlu dimulai dengan mengembangkan model mental baru tentang pekerja, bekerja, dan kerja. Model mental dikembangkan dengan bertitik tolak pada suatu keyakinan tentang pekerja (workwr) dan sikap kerjanya, serta tentang bekerja (working) dan kerja (work) itu sendiri.

Dimensi iklim kerja menurut (Utami; 2016) seperti kerja sama tim, kesesuaian pekerjaan, divisi pekerjaan, dan kebijakan
organisasi.Sedangkan menurut (Robert Stringer dalam Wirawan; 2007-131), iklim kerja meliputi dimensi stuktur (structure), komitmen (commitment), tanggung jawab (responsibility), penghargaan (recognition), dukungan (support), dan standar-standar (standards).

\section{Kepuasan Kerja}

Kepuasan kerja merupakan hal yang dimiliki oleh setiap orang dalam bekerja. Kepuasan kerja adalah sejauh mana individu merasa positif atau negatif tentang pekerjaan mereka, hal ini menunjukan sikap atau respon emosional terhadap tugas seseorang serta kondisi fisik dan sosial dari tempat kerja, ini menandakan bahwa jumlah perasaan positif secara keseluruhan individu memiliki terhadap pekerjaannya, selanjutnya (Ofori dan Aboagye; 2015).

Job satisfaction is a positive emotional state resulting from evaluating one's job experiences. Kepuasan kerja adalah keadaan emosi yang positif yang dihasilkan dari evaluasi pengalaman kerja seseorang (Mathis \& Jckson; 2016). Job satisfaction a positive feeling about a job resulting from an evaluation of its characteristics is clearly broad. Kepuasan kerja merupakan perasaan positif tentang pekerjaan yang dihasilkan dari evaluasi karakteristik secara luas dan jelas (Robbins \& Judge; 2013:79).

Kepuasan kerja merupakan hal yang dimiliki oleh setiap orang dalam bekerja. Kepuasan kerja adalah sejauh mana individu merasa positif atau negatif tentang pekerjaan mereka, hal ini menaunjukan sikap atau respon emosional terhadap tugas seseorang serta kondisi fisik dan sosial dari tempat kerja, ini menandakan bahwa jumlah perasaan positif secara keseluruhan individu memiliki terhadap pekerjaannya, selanjutnya (Anin, Ofori, \& Okyere, 2015). Job satisfaction is a positive emotional state resulting from evaluating one's job experiences. Kepuasan kerja adalah keadaan emosi yang positif yang dihasilkan dari evaluasi pengalaman kerja seseorang (Mathis \& Jckson; 2011).

Kepuasan kerja seorang karyawan berbedabeda karena setiap karyawan memiliki batasanbatasan sendiri sejauh mana seseorang merasakan puas. ketika karyawan menganggap bahwa mereka berhak lebih dari apa yang saat ini diterima, ketidakpuasan akan mengikuti, dan ini akan berlaku untuk aspek pekerjaan, seperti tingkat keterampilan, kesempatan untuk promosi, dan pengawasan (Kim, Choi, \& Seo, 2015)

Adapun dimensi kepuasan kerja dalam penelitian ini adalah dimensi kepuasan kerjayaitu turnover, tingkat absensi, umur, tingkat pekerjaan, ukuran organisas (Mangkunegara, 2011). Berdasarkan pemaparan diatas maka diambil paradigma penelitian sebagai berikut: 


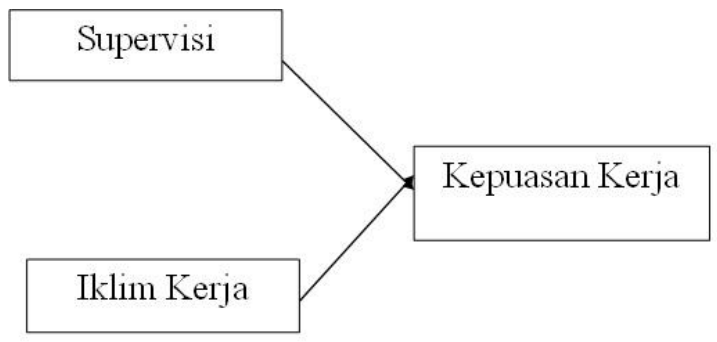

\section{Gambar 1: Paradigma Peneiltian}

\section{Metode Penelitian}

Unit analisis yang dijadikan responden dalam penelitian ini adalah karyawan PT. Tribuana Rekayasa. Oleh karena itu akan diteliti pengaruh supervisi dan iklim kerja tehadap kepuasan kerja karyawan PT. Tribuana Rekayasa. Penelitian ini dilakukan dalam kurun waktu kurang dari satu tahun, maka metode yang digunakan adalah cross sectional method, pengumpulan informasi dari subjek penelitian hanya dilakukan satu kali dalam satu periode waktu, sehingga penelitian ini merupakan cross sectional. Penelitian ini dilakukan pada bulan Agustus 2016 hingga Juli 2017.Populasi dalam penelitian ini adalah karyawan PT. Tribuana Rekayasa pada tahun 2017 sebanyak N: 67 karyawan. Pengambilan sampling jenuh dengan total responden sebanyak 67 karyawan.

Penelitian ini menggunakan teknik analisis data deskriptif yang digunakan untuk melihat pengaruh supervisi dan iklim kerja terhadap kepuasan kerja karyawan, dalam penelitian ini digunakan teknik analisis regresi linear berganda karena penelitian ini menganalisis tiga variabel yaitu supervisi, iklim kerja dan kepuasan kerja.

\section{Hasil Penelitian dan Pembahasan}

Berdasarkan kusioner yang disebar oleh peneliti, diperoleh data yang mengungkap distribusi responden berdasarkan demografi responden. Dari kuesioner data tersebut terungkap distribusi responden sebagai berikut:

Berdasarkan data jenis kelamin tampak bahwa dari 67 orang responden, 11 orang $(16,4 \%)$ di antaranya adalah responden perempuan, sedangkan 56 orang $(83,6 \%)$ lainnya adalah responden laki - laki. Dengan demikian dapat disimpulkan bahwa, komposisi responden penelitian ini sebagian besar didominasi oleh responden laki - laki.

Hasil yang berdasarkan pendidikan tertinggi bahwa dari 67 orang responden 25 orang $(37,3 \%)$ memiliki pendidikan tertinggi SMA/SMK, 18 orang $(26,9 \%)$ memiliki pendidikan tertinggi Diploma, 20 orang $(29,6 \%)$ memiliki pendidikan tertinggi S1, dan 4 orang (6\%) memiliki pendidikan tertinggi S2. Mengacu pada distribusi pendidikan tertinggi tersebut maka dapat disimpulkan bahwa, responden penelitian ini didominasi oleh responden yang memiliki pendidikan tertinggi yaitu SMA/SMK.

Distribusi usia responden bahwa, dari 67 orang responden 12 orang $(18 \%)$ di antaranya berusia antara $20-25$ tahun, 24 orang $(35,9 \%)$ di antaranya berusia antara 25-35 tahun, dan 12 orang atau (18\%) di antaranya berusia lebih dari > 25 tahun. 11 orang atau $(16,4 \%)$ di antaranya berusia lebih dari $31-35$ tahun, 8 orang atau (12\%) di antaranya berusia lebih dari 26-40 tahun. Mengacu pada distribusi usia respopnden di atas maka dapat disimpulkan responden penelitian ini didominasi oleh responden yang berusia antara 25-35 tahun.

Berdasarkan hasil analisis deskriptif masingmasing variabel penelitian dapat dijelaskan sebagai berikut:

Berdasarkan hasil penelitian dari kuesioner yang disebar kepada 67 responden diketahui bahwa supervisi PT. Tribuana Rekayasa menurut persepsi 3.735 dari skor kriterium atau jumlah maksimal perolehan nilai responden terletak pada daerah kriterium baik yaitu pada interval 3014 4020 dengan tingkat capaian $74,3 \%$. Sehingga dapat dikatakan bahwa dalam penelitian ini supervisi yang diterapkan PT. Tribuana Rekayasa telah berjalan dengan baik, namun pelaksanansupervisi perlu ditingkatkan lagi, karena semua dimensi berada di bawah skor ideal. Sama halnya dengan hasil penelitian (Sri Sarjana; 2012) yang menyatakan bahwavketerkaitan antara supervisi dengan kepuasan kerja karyawan sangat tinggi dan positif,

Berdasarkan hasil penelitian dari kuesioner yang disebar kepada 67 responden diketahui bahwa iklim kerja PT. Tribuana Rekayasa menurut karyawan mencapai skor 3.776dari skor kriterium atau jumlah maksimal perolehan nilai responden terletak pada daerah kriterium sedang yaitu pada interval 3015 - 4020 dengan tingkat capaian $75,1 \%$. Sehingga dapat dikatakan bahwa dalam penelitian ini iklim kerja yang di terapkan PT. Tribuana Rekayasa berjalan baik, namun perlu ditingkatkan lagi, karena semua dimensi berada di bawah skor ideal. Sama halnya menurut (Charles L. Salindeho; 2016) yang menunjukkan bahwa iklim kerja memiliki hubungan yang signifikan dengan kepuasan kerja.

Selain itu, hasil penelitian dari kuesioner yang disebar kepada 67 responden diketahui bahwa kepuasan kerja karyawan PT. Tribuana Rekayasa menurut karywan mencapai skor 3.4.4.0 dari skor kriterium atau jumlah maksimal perolehan nilai responden terletak pada daerah kriterium tinggi yaitu pada interval 2814 - 3752 dengan tingkat 
capaian $73,3 \%$. Sehingga dapat dikatakan bahwa dalam penelitian ini kepuasan kerja karyawan di PT. Tribuana Rekayasa sudah baik, namun perlu ditingkatkan lagi, karena semua dimensi berada di bawah skor ideal.

Berdasarkan pernyataan diatas penulis beranggapan bahwa supervisi dan iklim kerja berpengaruh terhadap kepuasan kerja karyawan. Karyawan yang merasa puas akan meningkatkan motivasi dan kinerja sehingga tujuan perusahaan tercapai. Oleh karena itu, perusahaan perlu memelihara supervisi dan iklim kerja agar karyawan merasa puas dalam bekerja dan terus bertahan pada perusahaan untuk mewujudkan tujuan perusahaan.

\section{Kesimpulan dan Rekomendasi}

Hasil penelitian menyatakan bahwa supervisi mempunyai pengaruh positif atau signifikan terhadap kepuasan kerja karyawan. Hal ini menunjukkan bahwa semakin baik supervisi, maka semakin baik pula kepuasan kerja karyawan tersebut maka penulis merekomendasikan agar karyawan dengan adanya supervisi dapat bekerja dengan baik dan melaksakan tugas pokoknya beserta fungsinya dalam suatu organisasi.

Hasil penelitian menyatakan bahwa, iklim kerja mempunyai pengaruh positif terhadap kepuasan kerja karyawan. Hal ini menunjukkan bahwa semakin baik iklim kerja, maka semakin baik pula kepuasan kerja karyawan maka penulis merekomendasikan agar perusahaanmemperhatikan iklim kerja dengan baik dan sesuai dengan terciptanya keadaan dan kondisi kerja yang nyaman sehingga karyawan akan merasa senang dan bekerja lebih bergairah

Supervisi dan iklim kerja mempunyai pengaruh yang positif terhadap kepuasan kerja karyawan. Hal ini menunjukkan bahwa semakin baik supervisi dan iklim kerja, maka akan semakin baik pula kepuasan kerja karyawan maka penulis merekomendasikan agar perusahaan menjaga dan menetapkan supervisi dan iklim kerja yang sudah terbentuk demi mencapai kepuasan kerja pada karyawan.

\section{DAFTAR PUSTAKA}

Akhter, N., Hussain. A., Bhatti, S. U. M., Shahid, F., \&Ullah, E. H. M. (2016). Impact of HR Practices on job Satisfaction: A Study on Teachers of Private and Public Sector. International Review of Management and Business Research, 5(2).
Chinthala, G. Mrs., (2014). Organizational Climate a Predictor of JobSatisfaction among Teachers. International Journal of Research (IJR)Vol-1, Issue-6,ISSN 23486848.

Dharma, A., (2014). ManajemenSupervisi. Jakarta: Raja GrafindoPersada.

Eded. (2016). Upaya meningkatkan kinerja dengan cara memberikan motivasi kerja dan menumbuhkan komitmen organisasional pegawai dinas perhubungan provinsi jawa barat, 1(2), 91-96.

Handoko, T. Hani. (2013) Manajemen. BPFE Yogyakarta : Yogyakarta

Hughes, J. M.. (2010). The Role of Supervision in Social Work: A critical analysis. Critical Social Thinking: Policy and Practice, (2).

Jovičić, A., Vujičić, D., Oreščanin, R., \& Lalić,D., (2013).Job Satisfaction In The Service Organizations In Serbia. Serbia. McPherson, L.,\&Macnamara, N. (2017). MengawasiPraktekPerlindunganAnak: Apa Yang Bekerja? PendekatanBuktiDiinformasikan. Australia.

Mangkunegara, Anwar Prabu. (2015). Effect of Work Discipline, Work Motivation and Job Satisfaction on Employee Organizational Commitment in the Company (Case Study in PT. Dada Indonesia). Jakarta. Indonesia

Masharyono. (2016). Physical Work Environment Effect on Employee Productivity of Textile Industry, 15, 630-632

Rivai, Veithzal. (2011).Manajemen Sumber Daya Manusia. Jakarta.

Robbins, Stephen P. dan Mary Coulter. (2013). Manajemen. EdisiKesepuluh. Jilid 2. Jakarta: Erlangga.

Salvador, J. T., Jade, S., \& Salvador, T. (2016).Transforming Organization through Instructional Leadership and Supervision (TOILS).European Scientific Journal, 12(31), 1857 - 7881, 1857- 7431.

Sangaran \& Jeetesh. (2015). The Effects of Job Satisfaction towards Employee Turnover in the Hotel Industry: A Case Study of Hotels in Kuala Lumpur City Center. 4, 2167 0269. Malaysia.

Senen, S. H. (2008). Pengaruh Motivasi Kerja dan Kemampuan Kinerja Karyawan pada PT. Saflindo Permata, 7(September), 1-15.

Sri, Sarjana., (2012). Pengaruh Supervisi Dan Iklim Organisasi Terhadap Kepuasan Kerja. Jurnal Kependidikan, 42 (2), 173 - 186. 
Sumiyati. (2016). Leader Member Exchange dan Kepribadian untuk Meningkatkan

Syamsul Hadi Senen. Masharyono. Nida

Triananda. Sumiyati. (2016). The Employee

Performance Influenced by

Communication: a Study of BUMD in

Indonesia. Indonesia

Tella, A., Ayeni, F., \&Popoola.(2007).Work

Motivation, Job Satisfaction and

Organisational Commitment of Library

Personnel in Academic and Research

Libraries in Oyo StateNigeria, 1522-0222.

Nigeria.

Utami, P. S., Hubeis, M., Affandi, M. J.(2016).

The Impact of Working Climate and

Motivation towards Job Satisfaction That

Implies the Employee Performance in PT

Indonesia Power Generation Business Unit of SuralayaBanten.International Journal of Scientific and Research Publications, 6(7), 2250-3153.

Employee Voice Kopontren DT, 11, 38-44.

Wirawan. (2007). Budaya dan Iklim Organisasi:
Teori Aplikasi dan Penelitian. Jakarta: Salemba Empat. 